\title{
Glosse
}

\section{ESC-Kongress: endlich Fakten statt Mythen}

_ Sinn und Zweck von Kongressen ist es, den Stand des Irrtums zu aktualisieren. Diesem Anspruch wurde der europäische Kardiologenkongress auch diesmal voll und ganz gerecht. Es wurde eine Reihe von Studien präsentiert, die manches Dogma ins Wanken gebracht haben. Sie zeigen, dass doch einiges in der Medizin eher der Tradition als der Evidenz geschuldet ist (siehe Report ab Seite 10).

Das Übergewicht ist bekanntlich der natürliche Feind des Kardiologen. Fast alles, womit er Tag für Tag konfrontiert wird, ist letztendlich Folge der Adipositas. Dass dies ein Klischee, ja ein diskri- minierendes Vorurteil ist, dafür sprechen die Daten einer Studie mit PCI-Patienten. Das Ergebnis: Nicht die Dicken, sondern die Dünnen sind das eigentliche Problem! Nicht Übergewicht sondern Untergewicht verschlechtert die Behandlungsergebnisse. Deshalb sollte man jedem Untergewichtigen dringend raten, vor der Herzkatheteruntersuchung einige Kilos an Gewicht zuzulegen. Sogar ein Mindestgewicht für die Koronarintervention ist im Gespräch.

Auch das Thema Ernährung ist stark von Mythen besetzt. Nun zeigte sich: Fette sind viel besser als ihr Ruf. Ob gesättigt oder ungesättigt, das ist egal, je mehr wir davon zu uns nehmen, umso länger leben wir. Wer hätte das gedacht! An der kardioprotektiven Wirkung der dunklen Schokolade zweifelt ja schon lange niemand mehr. Aber diese lässt sich optimieren, wenn die Schokolade mit Olivenöl angereichert wird. Das schmeckt zwar nicht besonders, aber Böses muss man ja mit Bösem vertreiben.

Und noch ein heikles Thema wurde (erneut) von der Wissenschaft aufgegriffen: Ist die Ehe gut oder schlecht für das Herz? Eindeutiges Ergebnis einer großen Studie: Verheiratete leben in der Tat länger, es kommt ihnen nicht nur so vor. -

Dr. Peter Stiefelhagen

\section{Androgenetische Alopezie: Am Hormonspiegel liegt es nicht}

\section{Dem Kahlschlag auf der Spur}

\section{Es scheint naheliegend zu vermuten, dass der durch Androgene bedingte Ausfall der Haupthaare mit dem Hormonspiegel assoziiert ist. Deutsche Forscher konnten das nicht bestätigen.}

_ Die Alopecia androgenetica ist die häufigste Form des Haarausfalls, jeder zweite Mann gehört im Alter von $50 \mathrm{zu}$ ihren Opfern. In vitro hemmen Testosteron, aber auch Östrogen das Haarwachstum. Ob die Sexualhormonspiegel eine Rolle bei der Alopezie spielen, haben Hanna Kische und Kollegen vom Institut für klinische Chemie der Universitätsmedizin Greifswald untersucht.

Als Probanden standen 373 Männer der „Study of Health in Pomerania“ (SHIP-Trend) zur Verfügung. Dabei ergab sich keinerlei Zusammenhang zwischen den Hormonspiegeln und der Alopezie.

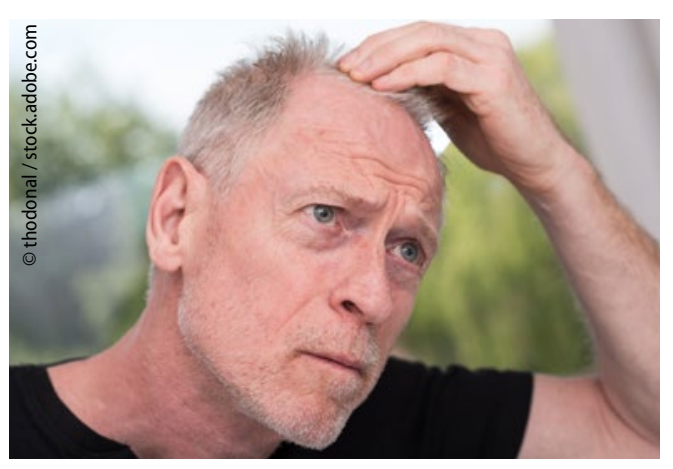

Mehr Androgenrezeptoren auf dem Kopf?

„Obwohl höhere Testosteronkonzentrationen über die 5-alpha-Reduktase den Dihydrotestosteronspiegel erhöhen und demzufolge die Androgenwirkung an den dermalen Papillenzellen der Haarfollikel stimulieren sollen, haben wir in der vorliegenden Studie keine Verbindung zwischen der Androgenkonzentration und dem Haarverlust von Männern feststellen können“, bilanzieren die Autoren. Resultate früherer Untersuchungen seien damit bestätigt.

Das heißt: Die androgenetische Alopezie geht vermutlich eher auf die Androgenempfindlichkeit bzw. auf die Dichte der Androgenrezeptoren zurück als auf die Serumkonzentrationen der Androgene selbst. 